\title{
Inflammatory mediators in overweight adolescents: association with insulin sensitivity, body composition and metabolic syndrome
}

\author{
R. Burrows, L. Leiva, A. M. Tong, J. Aldunate and E. Díaz \\ Institute of Nutrition and Food Technology, University of Chile, Chile
}

The insulin-resistance (IR) metabolic syndrome (MetS) leads to high CVD risk in adult life and has been associated with an early state of chronic low-grade inflammation (CLGI). The aim of the present study was to determine the association between a state of CLGI and insulin sensitivity, body composition and MetS prevalence in overweight adolescents. The study included 158 adolescents (BMI $\geq 85$ th percentile; eighty-six men) between 13 and 16 years of age, who were assessed for BMI, body composition (\% body fat mass (BFM) and $\%$ free-fat mass (FFM) by pletysmography, prevalence of MetS for three or more variables (waist circumference (WC) $\geq 90$ th percentile; HDL-cholesterol $\leq 400 \mathrm{mg} / \mathrm{l}$; TAG $\geq 1100 \mathrm{mg} / \mathrm{l}$; blood arterial pressure $\geq 90$ th percentile; fasting glucose $\geq 100 \mathrm{mg} / \mathrm{d}$ ), HOMA-IR (glucose $\times$ insulin/22.5) and the state of inflammation by C-reactive protein (CRP). Pearson correlation and $\psi^{2}$ were used to study associations between variables, OR to calculate risk and ANOVA and Tukey test to compare averages between groups. The median and ranges of CRP levels (mg/l) were 0.7 (range 0.04-9.1) in males and 0.7 (range 0.04-6.2) in females. CRP showed a correlation with BMI $(P<0.05)$, WC $(P<0.02)$, \% BFM $(P<0.05)$, \% FFM $(P<0.05)$, fasting insulin $(P<0.001)$ and HOMA $(P<0.001)$.

\begin{tabular}{lcc}
\multicolumn{3}{l}{ Table 1. Pearson correlation for CRP with variables of metabolic and cardiovascular risk } \\
\cline { 2 - 3 } Variable & $r$ & CRP \\
\hline BMI & 0.158 & $P$ \\
WC & 0.199 & $<0.05$ \\
$\%$ BFM & 0.168 & $<0.02$ \\
$\%$ FFM & 0.169 & $<0.05$ \\
Fasting insulin & 0.269 & $<0.05$ \\
HOMA & 0.259 & $<0.001$ \\
& & $<0.001$ \\
\hline
\end{tabular}

CRP was significantly $(P<0.01)$ associated with an anthropometric and metabolic cardiovascular risk profile. The prevalence and the risk of abdominal obesity (WC $\geq 90$ th percentile), IR (HOMA $\geq 3.3$ ) and MetS were significantly higher $(63 \%$, OR 3.0; 43\%, OR 4.1; $26 \%$, OR 4.1 respectively) in adolescents with CRP levels $\geq 1.12 \mathrm{mg} / \mathrm{l}$ ( $\geq$ tertile 2 ).

Table 2. Anthropometric, cardiovascular and metabolic profile across the CRP tertile distribution

\begin{tabular}{|c|c|c|c|c|c|c|c|}
\hline \multirow[t]{2}{*}{ CRP. } & \multicolumn{2}{|c|}{$<$ Tertile $1(<0.43 \mathrm{mg} / \mathrm{l})$} & \multicolumn{2}{|c|}{ Tertile $1-2(0.43-1.12 \mathrm{mg} / \mathrm{l})$} & \multicolumn{2}{|c|}{$>$ Tertile $2(>1.12 \mathrm{mg} / \mathrm{l})$} & \multirow[b]{2}{*}{$P$} \\
\hline & Mean & SD & Mean & SD & Mean & SD & \\
\hline BMI $\left(\mathrm{kg} / \mathrm{m}^{2}\right)$ & 2.0 & $0.5^{* *}$ & 2.4 & 0.8 & 2.5 & 1.1 & $<0.01$ \\
\hline $\mathrm{WC}(\mathrm{cm})$ & 88.1 & $6.5^{* *}$ & 92.5 & 7.4 & 95.4 & 10.8 & $<0.01$ \\
\hline $\mathrm{TBF}(\%)$ & 35.4 & 6.4 & 37.6 & 7.6 & 40.4 & $7.0 \dagger \dagger \ddagger$ & $<0.01$ \\
\hline FFM (\%) & 64.3 & 6.9 & 62.5 & 7.9 & 59.7 & $6.9+\dagger+$ & $<0.01$ \\
\hline HDL (mg/l) & 505 & 101 & 467 & 104 & 459 & $113 \dagger$ & $<0.05$ \\
\hline TAG (mg/l) & 995 & 495 & 1129 & 687 & 1271 & $697+\dagger$ & $<0.01$ \\
\hline HOMA & 1.9 & 1.2 & 2.3 & $1.3 \dagger$ & 3.4 & $2.6+4$ & $<0.001$ \\
\hline
\end{tabular}

These results confirm that (1) PCR levels in overweight adolescents are associated with a greater cardiovascular and metabolic risk and (2) IR involves inflammatory processes that may play an early role in the development of cardiovascular lesions. 